\title{
Using small-scale measurements to estimate hypolimnetic oxygen depletion in a deep lake
}

\author{
Robert Schwefel (D), ${ }^{1 *}$ Thomas Steinsberger (D), ${ }^{2,3}$ Damien Bouffard, ${ }^{1,2}$ Lee D. Bryant, ${ }^{4}$ Beat Müller, ${ }^{2}$ \\ Alfred Wüest (iD) 1,2 \\ ${ }^{1}$ Physics of Aquatic Systems Laboratory - Margaretha Kamprad Chair of Environmental Science and Limnology, ENAC, EPFL, \\ Lausanne, Switzerland \\ ${ }^{2}$ Eawag, Swiss Federal Institute of Aquatic Science and Technology, Kastanienbaum, Switzerland \\ ${ }^{3}$ Institute of Biogeochemistry and Pollutant Dynamics, ETH Zurich, Zurich, Switzerland \\ ${ }^{4}$ Research Unit for Water, Environment and Infrastructure Resilience (WEIR), University of Bath, Bath, United Kingdom
}

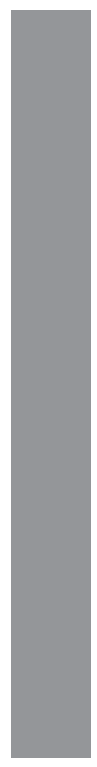

\begin{abstract}
Low oxygen concentrations in lakes and reservoirs are an ongoing environmental concern, particularly in light of increasing anthropogenic activity and climate change. Oxygen depletion processes in lakes are still not completely understood and a variety of models have been proposed based on limited field observations. Here, we present field measurements of oxygen depletion processes in a deep lake, Lake Geneva (Switzerland). The aim of this study was to quantify three basic processes controlling hypolimnetic oxygen depletion and their relative contribution to the total oxygen depletion (TOD) rate. Sediment oxygen uptake (SOU) and the flux of reduced substances were estimated based on oxygen microprofile measurements and sediment core data of reduced substances. Acoustic Doppler current profiler measurements and hydrodynamic modeling were used to ensure that SOU was measured under typical hydrodynamic conditions. Comparison with longterm monitoring data allowed for an estimate of the relative importance of SOU and water column mineralization (WCM). Results show a decrease in both SOU and WCM down to mid-depth which could not be explained by changes in hydrodynamic conditions or temperature. Below mid-depth, TOD increased due to an enhanced sediment area to water volume ratio $(\alpha)$. This vertical pattern of oxygen depletion is driven by (1) lake morphometry paired with increasing $\alpha$, and (2) decreasing organic matter mineralization in the water column with depth. The findings are explained by a model which separates the oxygen depletion into an exponentially decreasing component, representing the fast-decaying fraction of the organic matter, and a constant background component.
\end{abstract}

Efficient lake management is based on accurately describing and modeling physical and biogeochemical processes. Dissolved oxygen (DO) demand is one of the most important parameters for characterizing lake ecosystem health and, consequently, DO concentrations in lakes have been intensely studied since the end of the $19^{\text {th }}$ century (e.g., Thienemann 1928; Hutchinson 1957). Since the middle of the last century, anthropogenic pressure has caused eutrophication and temperature increases that negatively affect the DO budget of lakes and oceans. Thus, DO falls often below biologically acceptable concentrations (Diaz 2001; Friedrich et al. 2014; North et al. 2014).

*Correspondence: robert.schwefel@epfl.ch

Additional Supporting Information may be found in the online version of this article.
Increasing phosphorus concentrations were quickly identified as the main driver of eutrophication. Lake management has thus focused on reducing the phosphorus input to lakes, often with great success (Schindler 2006; Müller et al. 2014). Several empirical models have been developed to predict DO depletion rates based on phosphorus concentrations and other parameters, including temperature or lake geometry (Rast and Lee 1978; Cornett and Rigler 1979; Livingstone and Imboden 1996) and were tested empirically (Cornett and Rigler 1980; Rippey and McSorley 2009). However, the relationship between DO depletion and nutrient concentrations is complex and still poorly understood (Müller et al. 2012a; Scavia et al. 2014). DO depletion rates and primary production have remained high in many lakes despite significant reductions in nutrient inputs, as shown by Müller et al. (2012a) for several lakes on the Swiss Plateau including Lake Geneva, which is the focus of this study (Fig. 1). 

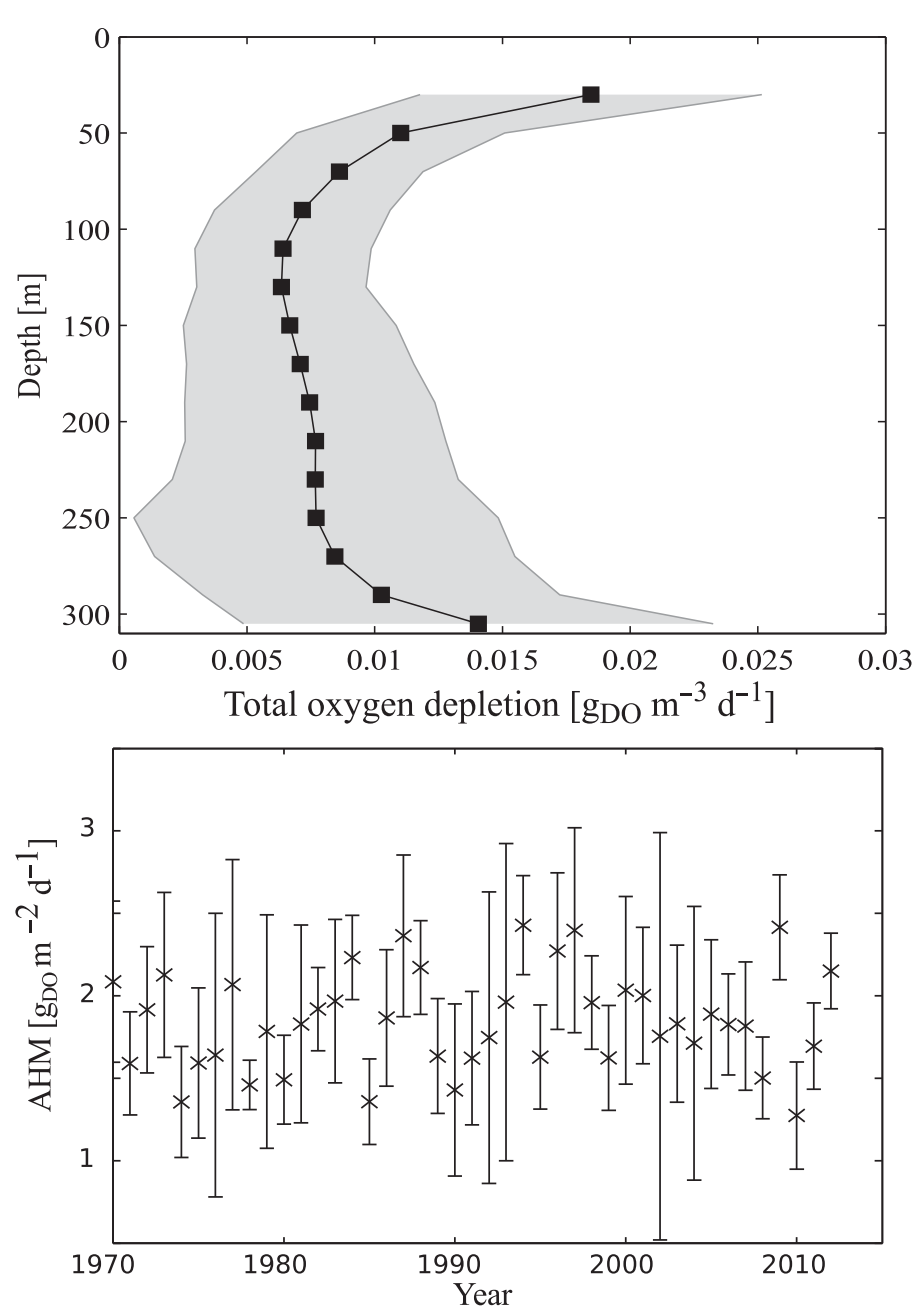

Fig. 1. Upper panel: Mean TOD and standard deviation for 1970-2012 as a function of depth. Lower panel: AHM as a function of time for the hypolimnetic water below $15 \mathrm{~m}$ depth.

Oxygen depletion is caused by mineralization of organic matter in the water column or within the upper sediments. Aerobic respiration is the dominant process for organic matter mineralization under oxic conditions. However, under anoxic conditions (e.g., in the deep water of meromictic lakes or in anoxic sediments), other electron acceptors come into play leading to the formation of reduced compounds including $\mathrm{CH}_{4}, \mathrm{NH}_{4}^{+}, \mathrm{Mn}(\mathrm{II})$, and $\mathrm{Fe}(\mathrm{II})$, as in the deep water of meromictic lakes or in anoxic sediments. These substances diffuse toward the oxic zones of the sediment or into the open water and are then oxidized, thereby contributing to further DO uptake. These fluxes of reduced substances can contribute significantly to DO depletion in eutrophic lakes (Gelda et al. 1995; Matzinger et al. 2010). Fluxes of reduced substances and oxic respiration depend on the mixing regime and on the availability and quality of organic matter. Fluxes of reduced substances between $0.1 \mathrm{~g}_{\mathrm{DO}}^{\mathrm{eq}} \mathrm{m}^{-2} \mathrm{~d}^{-1}$ and $0.5 \mathrm{~g}_{\mathrm{DO}}^{\mathrm{eq}} \mathrm{m}^{-2} \mathrm{~d}^{-1}$ were measured in several Swiss lakes
(Matzinger et al. 2010; Steinsberger et al. 2017) and were found to be proportional to the accumulation rate of organic carbon (Steinsberger et al. 2017). A schematic overview of the relevant processes for DO depletion in lakes is given in Fig. 2.

Long-term DO depletion measurements often rely on vertical DO profiles monitored at a single location within a lake. While time-series measurements at a singular point are useful for assessing long-term trends integrated over the entire waterbody, DO depletion is largely controlled by physical and biogeochemical processes at the sediment surface which may vary considerably over the entire lake waterbody. Thus, while much work has been done on the various sinks of DO depletion in large lakes (Cornett and Rigler 1979; Livingstone and Imboden 1996; Müller et al. 2012a), there is still a lack in comprehensive identification of the processes involved. Several studies addressing the interaction between bottom boundary layer (BBL) dynamics have revealed considerable short-term variability of DO depletion at the sediment in response to dynamic forcing (Lorke et al. 2003; Bryant et al. 2010a; Schwefel et al. 2017). Besides the shortterm variability, sediment oxygen uptake (SOU) depends on the efficiency of organic matter mineralization. The mineralization rate is in turn dependent on several parameters such as temperature (Gudasz et al. 2010) or organic matter quality (Arndt et al. 2013) which may show extensive variation within a lake. Current lake DO models use either simplified empirically derived expressions that do not quantitatively describe the complex processes upon which they are built (Fang and Stefan 2009; Rucinski et al. 2010) or they rely on a large number of free parameters that require calibration based on empirical field data (Rucinski et al. 2014). For both approaches, good knowledge of the sinks of DO and its spatial variability is crucial to improving the reliability and predictive power of the models. Hence, detailed measurements of the SOU at different lake depth and the relative importance of the flux of reduced substances for the total oxygen depletion (TOD) are essential to understand and reproduce oxygen depletion processes.

In this study, we investigate DO depletion in Lake Geneva, which is currently recovering from anthropogenic eutrophication but shows still high levels of DO depletion and periodic hypoxia in the deep hypolimnion (Schwefel et al. 2016). Sediment-water microprofile measurements were performed at different depths of the lake to determine the spatial variability of SOU (i.e., the flux of DO from the water toward the sediment surface). Simultaneous pore-water analyses of sediment cores allowed for the quantification of the fluxes of reduced substances out of the sediment. Combined with a set of long-term monitoring data from over more than $40 \mathrm{yr}$, collected from the water column at the deepest location of the lake, these observations allow for a distinction between the various pathways of DO consumption as a function of depth. The aims of this study were to 
a)

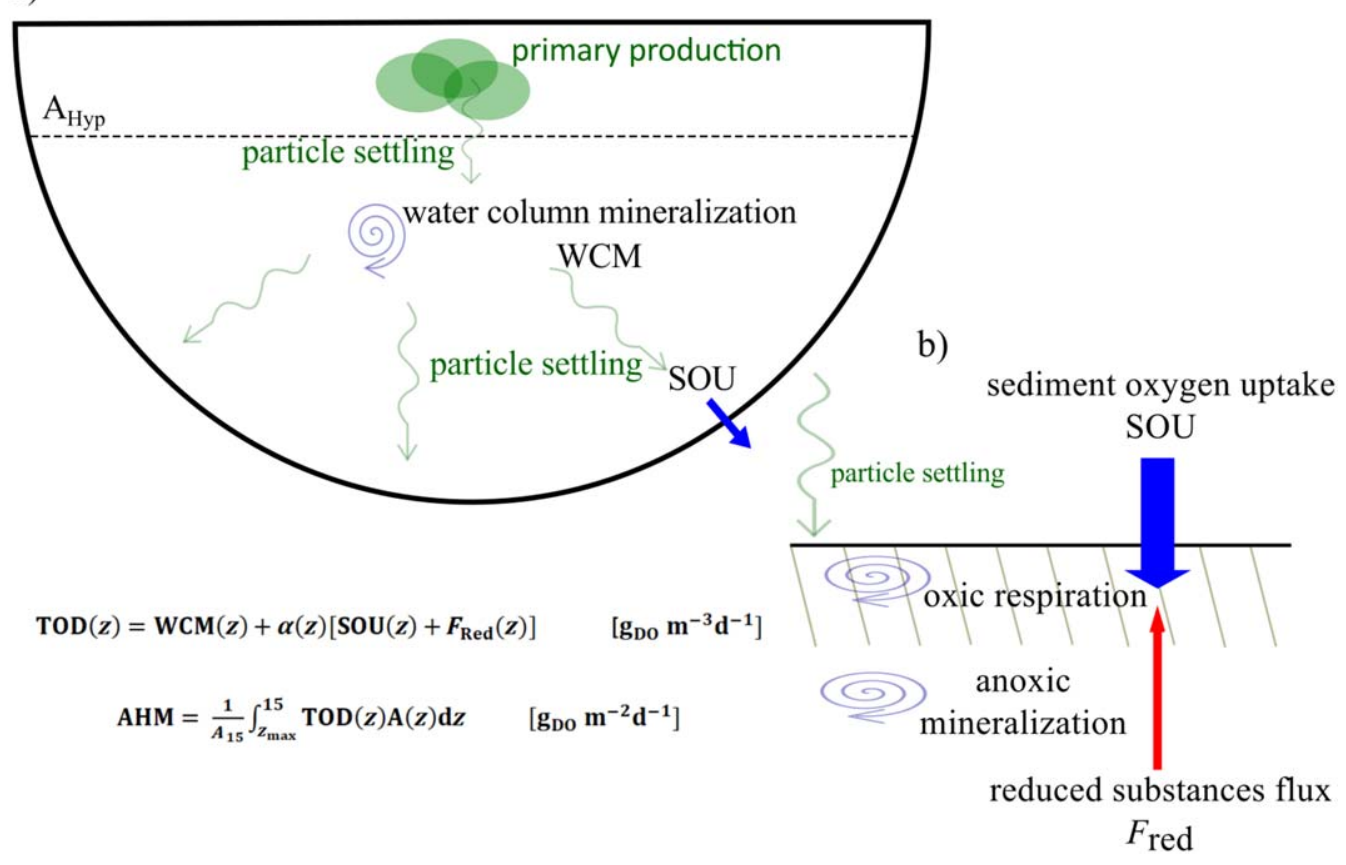

Fig. 2. Schematic illustration of oxygen depletion processes in the water column (a) and at the sediment surface (b). TOD is the total oxygen depletion $\left(g_{D O} \mathrm{~m}^{-3} \mathrm{~d}^{-1}\right)$ (Fig. 1), and SOU is sediment oxygen uptake $\left(g_{D O} \mathrm{~m}^{-2} \mathrm{~d}^{-1}\right.$ ) consumed directly by oxic respiration or partially indirectly by the reduced substances flux $F_{\text {red }}\left(g_{D O}^{\text {eq }} \mathrm{m}^{-2} \mathrm{~d}^{-1}\right) \cdot \alpha$ is the sediment surface to water volume ratio $\partial A / \partial V\left[\mathrm{~m}^{-1}\right]$. The AHM rate $\left(g_{D O} \mathrm{~m}^{-2} \mathrm{~d}^{-1}\right)$ integrates TOD over the hypolimnion.

(1) characterize the spatial distribution and variability of DO depletion, (2) estimate the relative importance of the two sediment molecular fluxes: the SOU and the reduced substances flux from the sediment, and (3) explain these findings within a conceptual basin-scale oxygen budget.

\section{Methods}

\section{Study site}

Lake Geneva is a deep perialpine lake situated on the border of France and Switzerland with a maximum and mean depth of $309 \mathrm{~m}$ and $153 \mathrm{~m}$, respectively, a surface area of $582 \mathrm{~km}^{2}$, and a volume of $89 \mathrm{~km}^{3}$. Once considered oligotrophic, Lake Geneva has experienced high nutrient inputs since the 1950s. Phosphorus concentrations increased from $15 \mathrm{mg} \mathrm{m}^{-3}$ around 1960 to up to $90 \mathrm{mg} \mathrm{m}^{-3}$ in the 1980s. Consequently, water transparency decreased, the phytoplankton communities shifted to species more typical for eutrophic environments, and phyto- and zooplankton biomass increased (Anneville and Pelletier 2000; Loizeau and Dominik 2005). While DO has been monitored in the deep hypolimnion since the late 1890s (e. g., Forel 1895; Delebecque 1898; Vivier 1944), low DO concentrations had never been observed prior to 1957 , either via direct field measurements (Delebecque 1898; Vivier 1944) or sediment core sampling (Jenny et al. 2014). Since then, periods of hypoxia have been observed regularly (Savoye et al. 2015; Fig. 3).

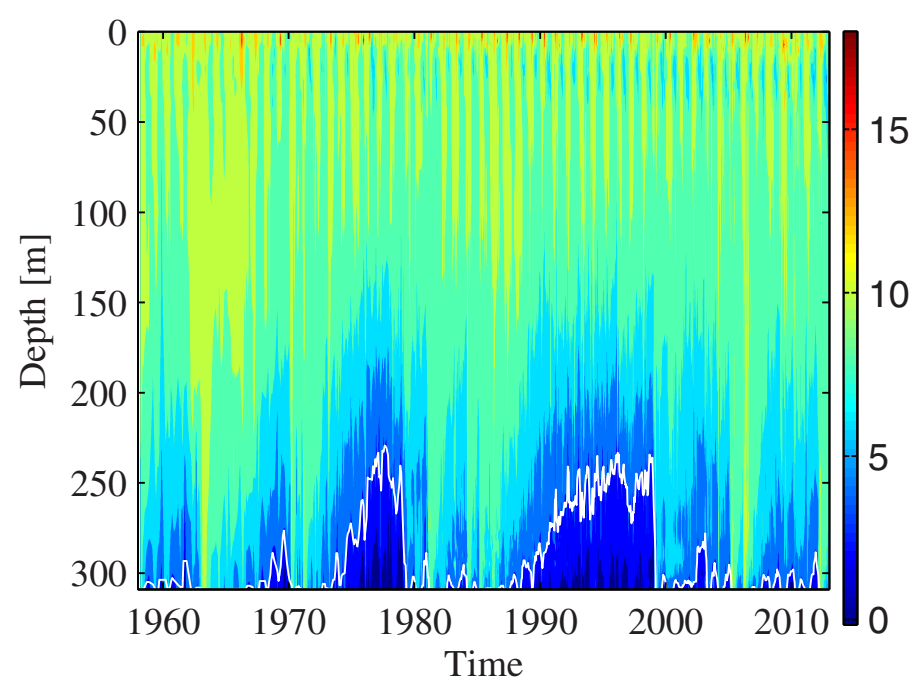

Fig. 3. Contour plot of $\mathrm{DO}\left[\mathrm{mg} \mathrm{L}^{-1}\right]$ at the long-term monitoring site SHL2, located at the deepest point of Lake Geneva (based on data from 1957 to 2012). The white line indicates the $4 \mathrm{mg} \mathrm{L}^{-1}$ contour line (running mean with 2-weeks half-window length), which defines the limit to hypoxic conditions.

Recent governmental measures to limit the phosphorus input into the lake reduced total phosphorus to the present concentrations of $\sim 20 \mathrm{mg} \mathrm{m}^{-3}$. Despite the high reduction in nutrient loads, total biomass has remained high and DO 
Table 1. Summary of the microprofile measurement results. The sediment oxic zone is defined as the layer, in which the oxygen concentration stays above $0.1 \mathrm{mg} \mathrm{L}^{-1}$.

\begin{tabular}{|c|c|c|c|c|c|c|c|c|}
\hline Number & $\begin{array}{l}\text { Depth } \\
(\mathrm{m})\end{array}$ & $\begin{array}{c}\text { \# of } \\
\text { profiles }\end{array}$ & $\begin{array}{c}\text { SOU } \\
\left(g_{\text {Do }} \mathrm{m}^{-2} \mathrm{~d}^{-1}\right)\end{array}$ & $\begin{array}{c}\text { DBL thickness } \\
(\mathrm{mm})\end{array}$ & $\begin{array}{l}\text { Sediment oxic } \\
\text { zone }(\mathrm{mm})\end{array}$ & $\begin{array}{c}\mathrm{BBL} \\
\text { temperature } \\
\left({ }^{\circ} \mathrm{C}\right)\end{array}$ & $\begin{array}{c}\text { BBL DO } \\
\text { concentration } \\
\left(\mathrm{g} \mathrm{m}^{-3}\right)\end{array}$ & Date \\
\hline MP2 & 45 & 12 & $1.08 \pm 0.33$ & $0.8 \pm 0.6$ & $2.4 \pm 0.5$ & 6.6 & 10.3 & Mar 2014 \\
\hline MP3 & 72 & 7 & $0.50 \pm 0.11$ & $1.5 \pm 0.8$ & $2.9 \pm 0.7$ & 6.6 & 10.1 & May 2014 \\
\hline MP4 & 76 & 13 & $0.46 \pm 0.16$ & $1.4 \pm 0.6$ & $3.8 \pm 1.0$ & 6.4 & 9.4 & Jul 2014 \\
\hline MP6 & 109 & 13 & $0.39 \pm 0.07$ & $1.7 \pm 0.4$ & $4.3 \pm 0.3$ & 5.9 & 8.7 & Jul 2014 \\
\hline MP7 & 133 & 13 & $0.21 \pm 0.06$ & $2.1 \pm 0.8$ & $5.0 \pm 0.8$ & 6.0 & 7.8 & Jul 2015 \\
\hline MP8 & 224 & 5 & $0.14 \pm 0.14$ & $1.9 \pm 1.2$ & $4.0 \pm 0.5$ & 5.8 & 4.5 & May 2017 \\
\hline
\end{tabular}
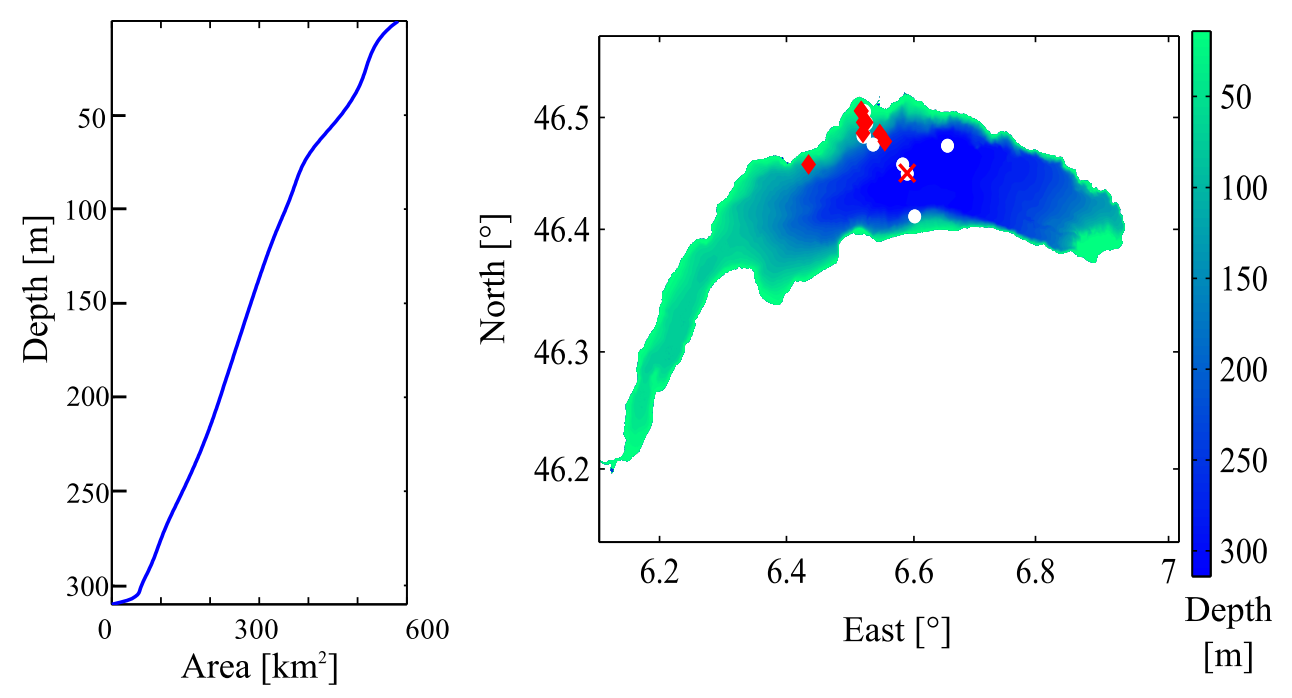

Fig. 4. Left panel: Bathymetry of Lake Geneva. Right panel: Measurement locations, red diamonds: microprofiles (Table 1, MP1 and MP2 as well as MP3 and MP4 are displayed as one point as they are too closely located to be resolved), white circles: sediment cores (Table 2), red cross: long-term monitoring point SHL2.

depletion rates and concentrations have not shown any significant trend over the last 40 yr (Anneville and Pelletier 2000; Savoye et al. 2015; Schwefel et al. 2016; Figs. 1, 3).

\section{Microprofile measurements}

In total, 97 DO profiles were measured using a MP4/ 8 Microprofiler (Unisense A/S) equipped with oxygen microsensors during eight different measurement campaigns between autumn 2013 and summer 2017 (Table 1). Measurements were performed in the northwestern part of the deep basin of Lake Geneva in depth between $43 \mathrm{~m}$ and $224 \mathrm{~m}$ (Table 1). The microprofiler was deployed for between $1 \mathrm{~d}$ and $3 \mathrm{~d}$ for each individual campaign; measurement locations and dates are shown in Fig. 4 and summarized in Supporting Information Table S1. The Clark-type oxygen microsensors had a tip size of $100 \mu \mathrm{m}$ with a detection limit of $0.01 \mathrm{mg} \mathrm{L}^{-1}$ and a response time of $<8 \mathrm{~s}$. The vertical spatial resolution of the measurements is limited by the diameter of the sensor tip. An RBR concerto data logger (RBR, Ottawa) equipped with an oxygen optode (Aanderaa Data Instruments) as well as a temperature and pressure sensor was attached to the microprofiler frame and positioned outside of the diffusive boundary layer (DBL) at $\sim 25 \mathrm{~cm}$ above the sediment to provide background time series of DO concentrations in the BBL. To calibrate the oxygen microsensors in the field, we performed a two-point, linear calibration with the in situ data from the optode as the upper reference point and the anoxic sediment as the lower reference point.

The detection of the sediment-water interface (SWI) is critical when investigating SOU. In Lake Geneva, sediment and water are distinctly separated by a defined SWI as observed during MIR submersible measurements in 2014 
(Wüest et al. 2014). As our instrument was very slowly but continuously sinking into the sediment throughout the experiments (by less than $1 \mathrm{~mm} \mathrm{~h}^{-1}$ ), we had to perform accurate SWI detection measurements prior to each profile. We programmed the microprofiler so that before each profile, the microsensor was first lowered continuously until the DO signal was reduced to $60 \%$ of the bulk BBL DO concentration. This drop was defined as a good proxy for identifying the close proximity of the DBL. Afterward, the sensors were raised by $\sim 7 \mathrm{~mm}$ and the high-resolution DO microprofile measurements were started in typically 150-300 vertical steps of $100 \mu \mathrm{m}$ fully covering the water-side DBL and the sediment oxic zone beneath. Per profile, sediment detection and profiling generally lasted about $70 \mathrm{~min}$ and varied depending on the number of steps and the time needed for sediment detection. Final determination of the SWI was based on visual identification of the gradient change in the DO profiles across the SWI that results from differing diffusivities between water and sediment (Røy et al. 2004; Bryant et al. 2010b). Analysis of the DO variance provided additional evidence for the correct location of the SWI (Schwefel et al. 2017).

The SOU was estimated from the water-side DO gradient based on Fick's law:

$$
\mathrm{SOU}=D \frac{\partial \mathrm{O}_{2}}{\partial z}
$$

where $D$ is the temperature-dependent molecular diffusion coefficient of oxygen in water. $\frac{\partial \mathrm{O}_{2}}{\partial z}$ is the DO gradient in the linear region above the SWI where $z$ is defined positive downward. Hence, positive values indicate fluxes into the sediment. The lower boundary of the sediment oxic zone was defined by the depth where DO concentrations fell below $0.1 \mathrm{mg} \mathrm{L}^{-1}$ ( $\sim 3 \mu \mathrm{mol} \mathrm{L} \mathrm{L}^{-1}$ as in Bryant et al. 2010a). Finally, the thickness of the DBL was calculated by extrapolating $\frac{\partial \mathrm{O}_{2}}{\partial z}$ up to the point where $\mathrm{DO}(z)$ reaches the averaged bulk DO concentrations of the BBL. In Jørgensen and Revsbech (1985), this term is called the "effective DBL."

\section{Current measurements and modeling}

Flow measurements were performed with an upwardlooking $2 \mathrm{MHz}$ acoustic Doppler current profiler (ADCP; Nortek Aquadopp). The ADCP was deployed close to the microprofiler ( $100 \mathrm{~m}$ away) to quantify the BBL flow at the same time as the SOU estimate. During all deployments, the vertical resolution was $5 \mathrm{~cm}$. Due to the blanking distance of the ADCP, the first measurement cell was $\sim 20 \mathrm{~cm}$ above the sediment. Measurements were performed in burst mode in 20 min intervals with 256-1024 measurements per burst. Due to instrument and/or deployment issues, velocity data were not available for all deployments (see Supporting Information Table S1).

The hydrodynamic conditions of the four relatively short ( $<1$ week) measurements periods were compared to typical

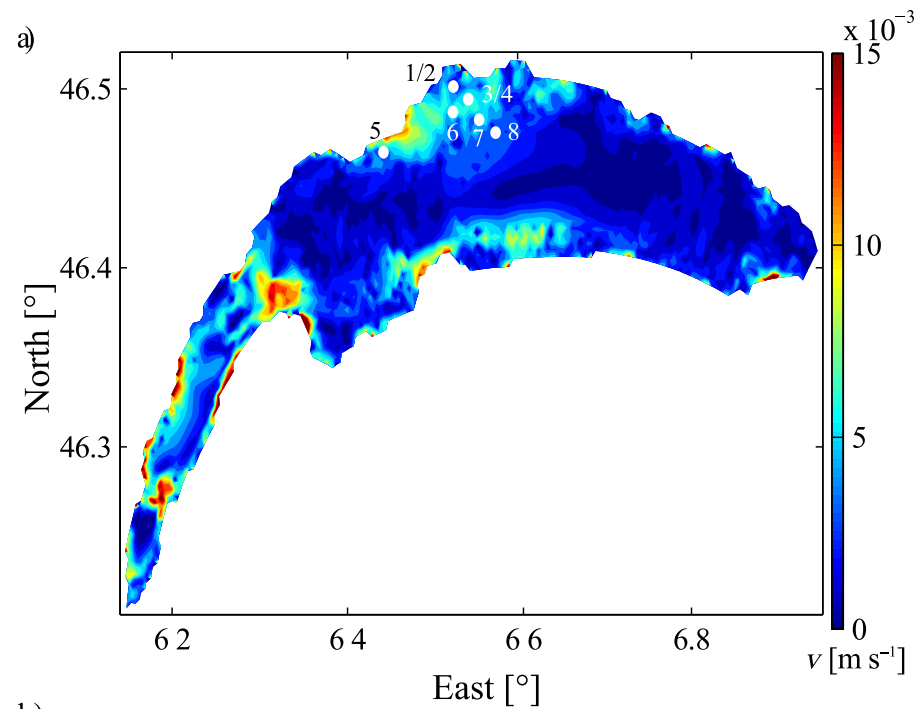

b)
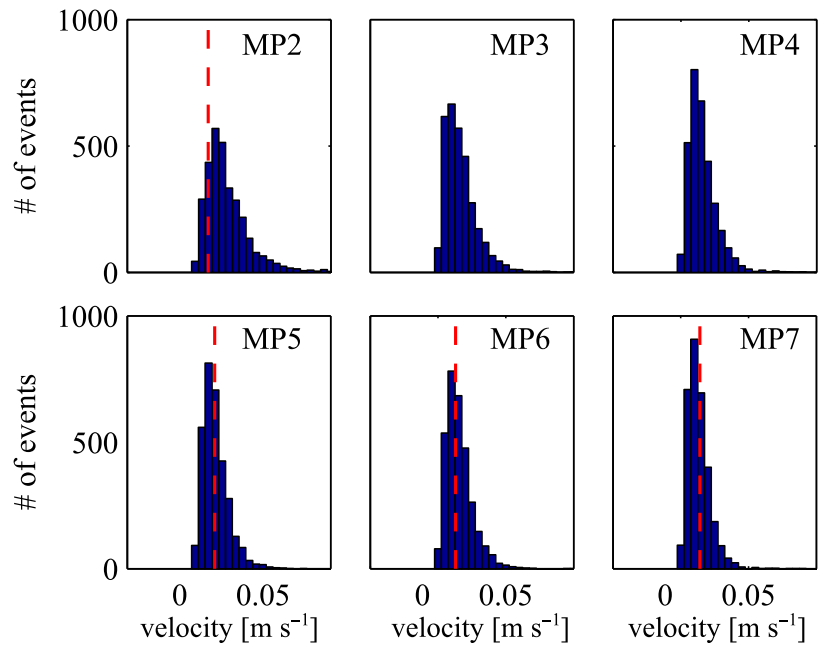

Fig. 5. (a) Contour plot of mean current speed $1 \mathrm{~m}$ above the sediment during the year 2012 according to the 3D hydrodynamic model DELFT 3D. (b) Histograms of the modeled current speed 2012 at the measurement sites (MP2-MP7, white dots in panel a; for exact coordinates, see Supporting Information Table S1). The red dashed line gives the mean observed velocities $1 \mathrm{~m}$ above bottom measured by an ADCP during the microprofile measurements. For measurements MP1, MP3, MP4, and MP8, no ADCP data were available.

conditions in Lake Geneva by using the three-dimensional hydrodynamic model Delft3D (Razmi et al. 2013). The model provided a map of the average speed of the BBL currents at $1 \mathrm{~m}$ above the sediment during the year 2012. Over a 1 yr period, we observed a clear decrease in the bottom currents with depth, as shown in the contour map in Fig. 5a and in the frequency distribution at different measuring locations in Fig. 5b. The modeled bottom current distribution indicates that at the $43 \mathrm{~m}$ deep site, measurements were collected during comparatively quiet conditions compared to long-term BBL currents at this location. During the measurements at the deeper sites, the flows were close to the modeled mean bottom currents (Fig. 5b). 
Table 2. Flux of reduced substances in units of oxygen equivalents $\left(g_{D O}^{e q} m^{-2} d^{-1}\right)$ using Eq. 2 .

\begin{tabular}{|c|c|c|c|c|c|c|c|c|c|}
\hline & LG1 & LG2 & LG3 & LG4 & LG5 & LG6 & LG7 & LG8 & Mean \\
\hline Methane & 0.029 & $<0.001$ & 0.003 & 0.035 & 0.051 & 0.039 & 0.005 & 0.056 & $0.027(55 \%)$ \\
\hline Manganese(II) & $<0.001$ & 0.003 & 0.002 & 0.004 & 0.001 & 0.002 & 0.006 & 0.005 & $0.003(6 \%)$ \\
\hline Iron(II) & 0.003 & 0.002 & 0.003 & 0.006 & 0.002 & $<0.001$ & 0.002 & $<0.001$ & $0.002(4 \%)$ \\
\hline Sum & 0.049 & 0.032 & 0.018 & 0.064 & 0.086 & 0.055 & 0.021 & 0.071 & 0.049 \\
\hline
\end{tabular}

\section{Sediment cores}

A total of 16 sediment cores were collected with a UWITEC corer equipped with a PVC tube $(6.5 \mathrm{~cm}$ inner diameter, $60 \mathrm{~cm}$ length) at eight different sites from $40 \mathrm{~m}$ to $310 \mathrm{~m}$ depth (Fig. 4; Table 2). At each site, one core was sampled for the analysis of $\mathrm{CH}_{4}$ via gas chromatography and a second core was sampled for the measurement of pore-water concentrations of cations and anions using capillary electrophoresis (Kubán̆ et al. 2007; Torres et al. 2013).

For pore-water retrieval, PVC tubes with pre-drilled holes of $2 \mathrm{~mm}$ diameter at $5 \mathrm{~mm}$ vertical intervals were used. The holes were sealed with adhesive tape prior to sampling. Resolution of the measurements was $0.5 \mathrm{~cm}$ for the first $10 \mathrm{~cm}$ and $1 \mathrm{~cm}$ for the next $10 \mathrm{~cm}$ of the sediment. Immediately upon retrieval, the cores were brought to the lab and 10-50 $\mu \mathrm{L}$ of sediment pore water were sampled by insertion of a MicroRhizon filter tube ( $1 \mathrm{~mm}$ diameter, $0.20 \mu \mathrm{m}$ pore size; Rhizosphere Research Products) through the pre-drilled holes. Additionally, one sample was taken from the overlying water. Measurements were performed with two portable capillary electrophoresis systems equipped with capacitive coupled contactless conductivity detectors. Cations were analyzed in all eight cores. The analysis of anions was omitted for logistical reasons in the 2014 campaign. Full separation of cations of interest $\left(\mathrm{NH}_{4}^{+}, \mathrm{Mn}(\mathrm{II})\right.$, and $\left.\mathrm{Fe}(\mathrm{II})\right)$ was achieved within 6 min. Standard deviations of all measurements were $<5 \%$. The setup is described in detail by Torres et al. (2013) and Steinsberger et al. (2017).

For the $\mathrm{CH}_{4}$ measurements, holes of $1.2 \mathrm{~cm}$ diameter were drilled staggered at $1-\mathrm{cm}$ vertical intervals in the sediment sampling tube and covered with adhesive tape. Immediately after retrieval, cores were sampled from top to bottom by cutting the tape and inserting a plastic syringe which had the tip cut off. Two milliliters of sediment were transferred into $125 \mathrm{~mL}$ serum flasks prefilled with $2 \mathrm{~mL}$ of $7 \mathrm{M} \mathrm{NaOH}$ and sealed with butyl rubber stoppers. Methane was analyzed by headspace gas chromatography (Agilent) using a 1010 Supelco Carboxene column.

The fluxes of reduced substances $\left(F_{\mathrm{CH} 4}, F_{\mathrm{NH} 4}, F_{\mathrm{Mn}}\right.$, and $F_{\mathrm{Fe}}$ for $\mathrm{CH}_{4}, \mathrm{NH}_{4},{ }^{+}, \mathrm{Mn}(\mathrm{II})$, and $\mathrm{Fe}(\mathrm{II})$, respectively) were calculated based on the concentration gradients measured in the topmost layer of the sediment cores. A one-dimensional balance model originally developed by Epping and Helder
(1997) for oxygen and adapted to other dissolved substances was used to estimate species fluxes. The model, a reactiondiffusion model based on the assumption of steady-state conditions in the sediment, is described in detail in Müller et al. (2003) and Steinsberger et al. (2017). The modeled fluxes of reduced substances were then converted to oxygen equivalents based on redox stoichiometry (Matzinger et al. 2010) by:

$$
F_{\text {red }}=2 F_{\mathrm{CH} 4}+2 F_{\mathrm{NH} 4}+0.5 F_{\mathrm{Mn}}+0.25 F_{\mathrm{Fe}}
$$

where $F_{\text {red }}$ represents the sum of all reduced substances (estimated in $\left[\mathrm{mol} \mathrm{m} \mathrm{m}^{-2} \mathrm{~d}^{-1}\right]$ ) and expressed in oxygen equivalents [g $\mathrm{g}$ eq $\mathrm{m}^{-2} \mathrm{~d}^{-1}$ ] by using Eq. 2 .

\section{Monitoring data}

Since 1957, DO measurements were performed on a regular basis by the Commission International pour la Protection des Eaux du Léman (CIPEL). DO was measured along with other parameters (e.g., total phosphorus, transparency, and temperature) at the deepest point of the lake (SHL2, see Fig. 4) throughout the entire water column for 8-12 times per year between 1957 and 1970 and at least once per month thereafter to present. Comparisons between the measured DO concentrations in the water column of SHL2 and four other offshore measurement stations at six different depths show only minor variations of $6 \%$ on average with higher variability in spring as compared to summer and autumn (Supporting Information Fig. S1). Therefore, data from SHL2 was considered to be representative for the entire lake during stratified summer conditions.

\section{Results}

\section{Microprofile measurements}

Two typical microprofiles from $45 \mathrm{~m}$ and $133 \mathrm{~m}$ depth (Table 1) are shown as representative examples in Fig. 6. The BBL temperatures were measured simultaneously with the DO microprofiles during each deployment. While BBL temperatures showed only minor differences between individual measurements, BBL DO concentrations decreased with depth and were, as expected, lower in autumn compared to spring and summer (Table 1). The mean SOU, sediment oxic zone depth (i.e., oxygen penetration depth), and BBL temperature 


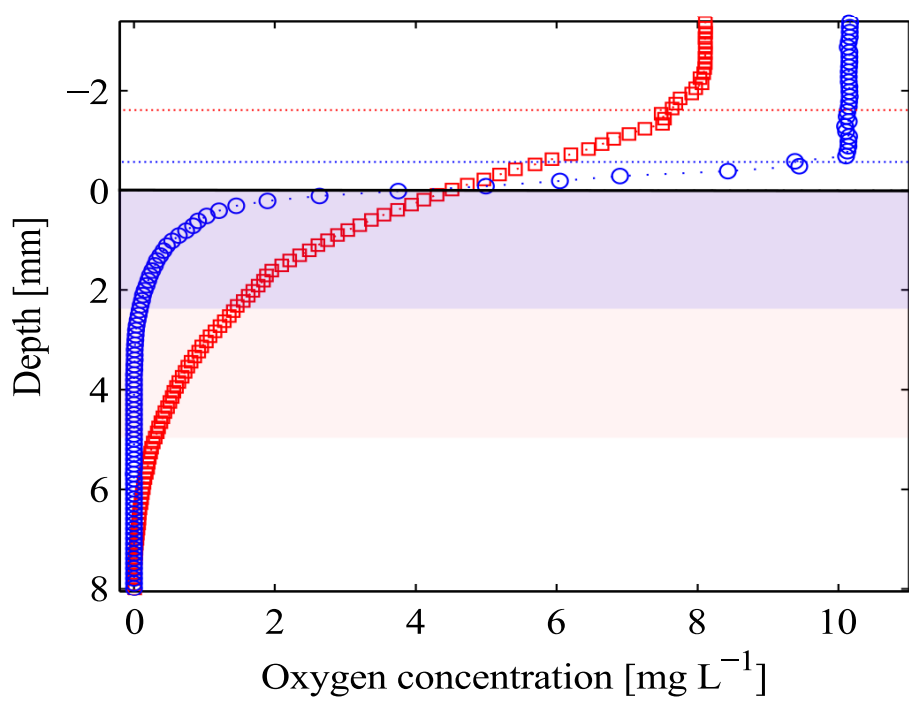

Fig. 6. Two examples of DO microprofiles obtained at $45 \mathrm{~m}$ (blue) and at $133 \mathrm{~m}$ (red) depth. Dotted lines show the upper end of the DBL. The thickness of the sediment oxic zone at $45 \mathrm{~m}$ is defined in light blue light blue (2.1 $\mathrm{mm}$ penetration depth) and in light red at $133 \mathrm{~m}$ depth (5.0 $\mathrm{mm}$ penetration depth).

and DO concentration at the different measurement sites are summarized in Table 1 . Figure 7 shows the variation of SOU with depth. The individually estimated SOU rates, based on averages from 4 to 30 profiles per site, varied strongly during each measurement session (Table 1). These variations can be partially explained by BBL turbulence dynamics that was also observed in other studies (Lorke et al. 2003; Bryant et al. $2010 a$ ). In addition to temporal variations in the individual profiles at each site, SOU also showed strong spatial variability among the different measurement sites with a distinct decrease with depth ranging from $1.08 \pm 0.51 \mathrm{~g}_{\mathrm{DO}} \mathrm{m}^{-2} \mathrm{~d}^{-1}$ at $45 \mathrm{~m}$ depth to only $0.14 \pm 0.14 \mathrm{~g}_{\mathrm{DO}} \mathrm{m}^{-2} \mathrm{~d}^{-1}$ at $224 \mathrm{~m}$ depth.

In parallel, the sediment oxic zone increased with depth from $\sim 2 \mathrm{~mm}$ at $43 \mathrm{~m}$ depth to $\sim 5 \mathrm{~mm}$ at $133 \mathrm{~m}$ depth (Table 1). At $224 \mathrm{~m}$, the sediment oxic zone was slightly shallower $(4 \mathrm{~mm})$, which was most likely due to the generally lower oxygen concentrations present during measurements at this depth.

\section{Sediment cores}

In the top few millimeters of the sediment, DO is depleted by two processes: (1) aerobic respiration in the sediment and (2) reduced substances fluxes from the deeper sediment (Fig. 2). The latter leads to a DO consumption if the reduced substances diffuse into the oxic zone of the sediment. An unknown fraction of the reduced substances is oxidized in the sediment, thereby contributing to the SOU (Frenzel et al. 1990; Bryant et al. 2011). The remaining fraction diffuses out of the sediment where it is oxidized in the overlying oxic water column (as quantified by $F_{\text {red }}$ ).

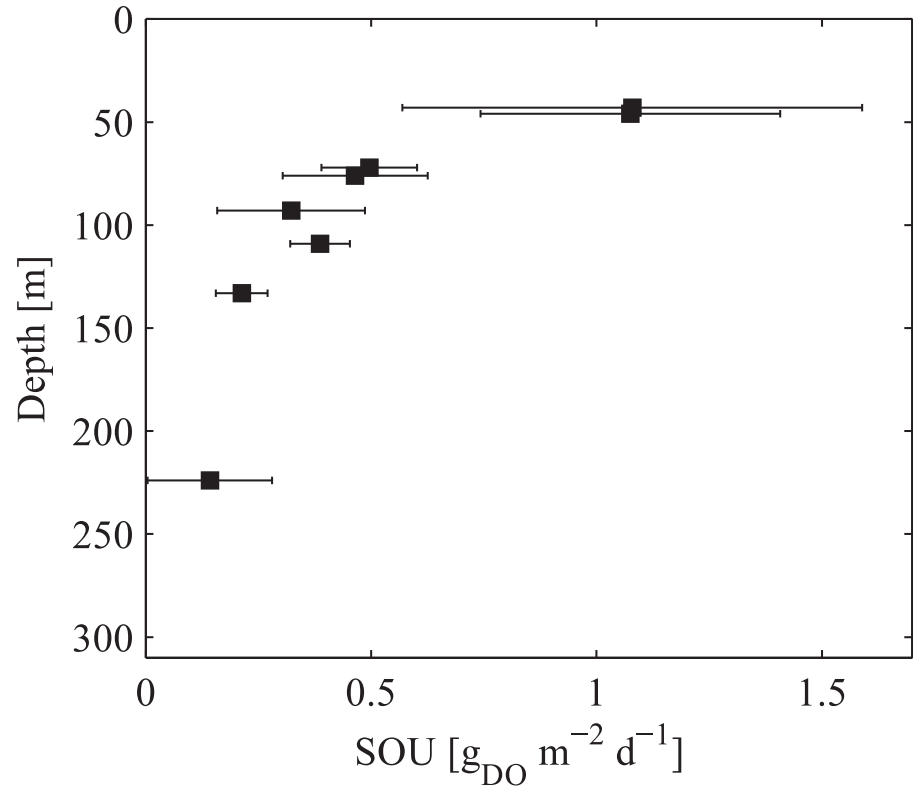

Fig. 7. Estimated SOU (averaged values over 4-30 profiles per measurement site) as a function of depth. Error bars show the standard deviation of each measurement campaign.

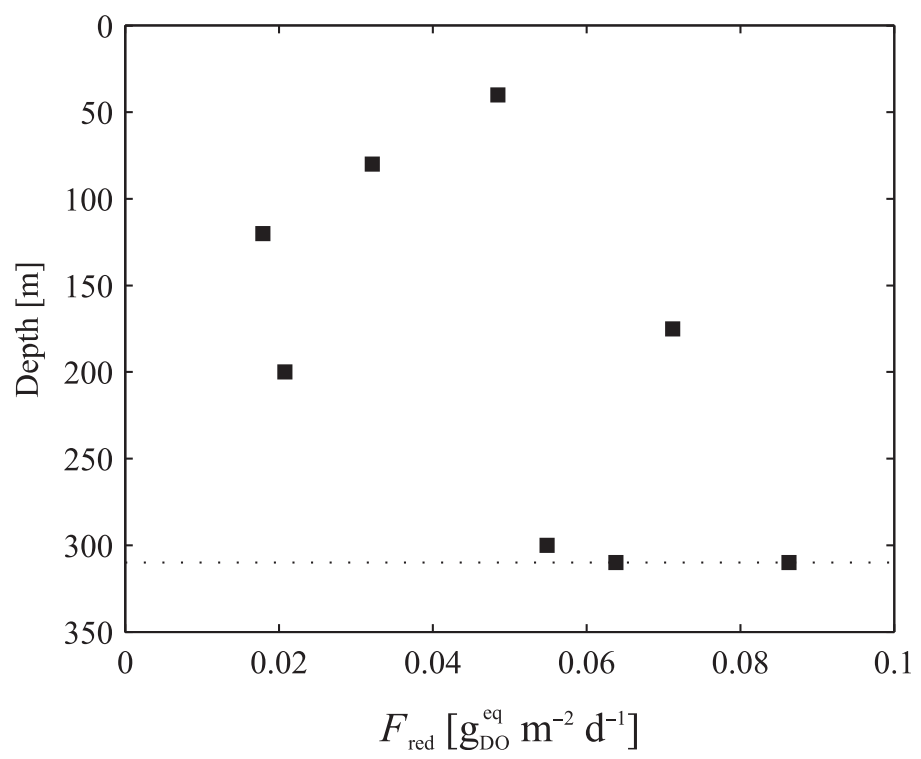

Fig. 8. Flux of reduced substances, $F_{\text {red, }}$ from the sediment to the water as a function of depth expressed in oxygen equivalents $\left(g_{\mathrm{DO}}^{\mathrm{eq}} \mathrm{m}^{-2}\right.$ $\mathrm{d}^{-1}$ ). The dotted line shows the maximal depth of $309 \mathrm{~m}$.

$F_{\text {red }}$ was calculated based on the sediment pore-water concentrations of reduced substances and converted to oxygen equivalents according to Eq. 2. $F_{\text {red }}$ varied from only 0.018 g eq $\mathrm{m}^{-2} \mathrm{~d}^{-1}$ to $0.086 \mathrm{~g}_{\mathrm{DO}}^{\text {eq }} \mathrm{m}^{-2} \mathrm{~d}^{-1}$ with a mean of $0.049 \pm 0.024 \mathrm{~g}_{\text {DO }}^{\text {eq }} \mathrm{m}^{-2} \mathrm{~d}^{-1}$ among the different measurement sites (Fig. 8; Table 2), which is only $3.6 \%$ of the total hypolimnetic oxygen depletion in Lake Geneva and is 
extremely small compared to medium-sized lakes with comparable eutrophication histories (Matzinger et al. 2010;

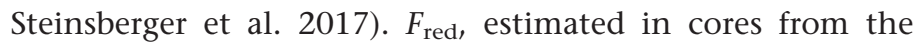
deepest lake zones of $\sim 300 \mathrm{~m}$, varied between $\sim 0.06 \mathrm{~g}$ DO $\mathrm{m}^{-2} \mathrm{~d}^{-1}$ and $0.09 \mathrm{~g}_{\text {DO }}^{\text {eq }} \mathrm{m}^{-2} \mathrm{~d}^{-1}$. Cores taken at sites between $40 \mathrm{~m}$ and $200 \mathrm{~m}$ depth showed generally lower $F_{\text {red }}$ fluxes (0.02-0.05 $\left.\mathrm{g}_{\text {DO }}^{\text {eq }} \mathrm{m}^{-2} \mathrm{~d}^{-1}\right)$. An exception is core LG7, taken at depth $200 \mathrm{~m}\left(0.07 \mathrm{~g}_{\mathrm{DO}}^{\text {eq }} \mathrm{m}^{-2} \mathrm{~d}^{-1}\right)$, where $F_{\text {red }}$ is comparatively high, but still very low in absolute terms. This particular site, however, may be influenced by the close proximity of the City of Evian or the inflow of the river Dranse which could lead to locally increased organic matter concentrations due to wastewater inputs. Unfortunately, no microprofile measurements were performed to characterize sediment-water oxygen dynamics at this location as the steep bathymetry is not well suited for microprofiler stability. At sites where parallel microprofile and sediment core measurements were obtained (LG1, LG2, and LG3; Table 2 ), $F_{\text {red }}$ was consistently less than $10 \%$ of SOU. The most dominant reduced substances were $\mathrm{CH}_{4}$ and $\mathrm{NH}_{4}^{+}$(Table 2), which is consistent with measurements in other Swiss lakes (Matzinger et al. 2010; Steinsberger et al. 2017).

\section{BBL turbulence}

BBL turbulence depends on the wind forcing prior to the measurement period. During microprofiling, the highest BBL turbulence was measured at $133 \mathrm{~m}$; the lowest was at $45 \mathrm{~m}$ due to calm conditions shortly before the microprofiler deployment. All measurements were performed under hydrodynamic conditions typical for Lake Geneva, as shown by the comparison with the Delft3D model flows in the BBL (Fig. 5b). While DO flux and DBL thickness varied at each site depending on turbulent conditions, mean values of DO fluxes were considerably higher at the shallowest measurement site which also had the lowest BBL currents. In turn, DBL thickness tended to increase with depth.

\section{Long-term monitoring data}

For the years 1970-2012, monthly DO concentration data were interpolated spatially and temporally and the areal hypolimnetic mineralization (AHM) rate $\left(\mathrm{g}_{\mathrm{DO}} \mathrm{m}^{-2} \mathrm{~d}^{-1}\right.$; Fig. 2) as well as the TOD rate $\left(g_{D O} m^{-3} d^{-1}\right)$ per depth layer were determined based on the linear decrease in DO during summer stagnation (Fig. 3). While TOD is a measure of the DO depletion per volume in every depth layer during summer (Fig. 2), AHM integrates the summer DO depletion (for $\sim 180 \mathrm{~d}$ ) over the entire hypolimnion (from the sediment to a water depth of $15 \mathrm{~m}$; see definition in Fig. 2). Although AHM varied considerably with a mean value of $1.34 \pm 0.34$ $\mathrm{g}_{\mathrm{DO}} \mathrm{m}^{-2} \mathrm{~d}^{-1}$, AHM shows no significant trend during the entire observed period. An analysis of the vertical structure of DO depletion rates shows that TOD decreases with depth down to $\sim 150 \mathrm{~m}$. Below $150 \mathrm{~m}$ depth, TOD increases again (Fig. 1). At each depth, the fraction of oxygen depletion caused by SOU (Fig. 7) was found to be significantly lower than TOD.

\section{Discussion}

\section{SOU and sediment oxic zone depth}

Despite strong variability in the physical boundary conditions, all microprofile measurements showed a consistent decrease of SOU with lake depth (Fig. 7). Measurement dates ranged from March to October, mostly during summer (June-August). Because of temporal variations and differing lake depths, DO concentrations in the BBL varied between $10 \mathrm{mg} \mathrm{L}^{-1}$ and $7.8 \mathrm{mg} \mathrm{L}^{-1}$ in the measurements above $150 \mathrm{~m}$. In the measurement at $224 \mathrm{~m}$ depth, BBL DO concentration was $4.5 \mathrm{mg} \mathrm{L}^{-1}$. Since the microprofiler was always deployed well below the thermocline, BBL temperatures varied only by $\sim 0.8^{\circ} \mathrm{C}$ and did not alter organic matter mineralization and oxygen depletion significantly (Gudasz et al. 2010). DO fluxes are partially dependent on the difference in DO concentrations between SWI and the BBL above the DBL (Eq. 1). Hence, lower BBL DO concentrations directly imply lower DO fluxes into the sediment. Nevertheless, the variation of measured SOU with lake depth was too high to be a result of this effect only. During measurements, the standard derivation of SOU was typically on the order of $\sim 30 \%$ and some individual measurements were found to be more than 100\% higher than the mean values. Per Eq. 1, these variations can partially be explained by (1) varying DO concentration differences between SWI and bulk BBL (Fig. 6) and/or (2) varying DBL thicknesses due to changes in BBL turbulence (Lorke et al. 2003; Bryant et al. 2010a; Schwefel et al. 2017). Based on microprofile measurements in Lake Alpnach, increased SOU has been shown to directly correlate with increased turbulence and decreased DBL thickness (Bryant et al. 2010a,b). However, the relationship between BBL turbulence and SOU could not explain the systematic decrease of SOU with lake depth in Lake Geneva. The estimated differences in the averaged SOU at $43 \mathrm{~m}$ and $224 \mathrm{~m}$ depth were $\sim 700 \%$ while changes in BBL current speed were only $\sim 50 \%$ (Fig. 5). During measurements at the shallowest site, which had the highest SOU, currents and, in turn, BBL turbulence was even lower than at the deeper sites, all of which had lower SOU rates (Fig. 5b).

DO depletion in the sediment depends on the amount of organic matter and its quality (Steinsberger et al. 2017). While parts of organic material are easily degradable (i.e., labile) and decompose relatively quickly, other parts degrade over longer time scales (Kristensen and Holmer 2001; Arndt et al. 2013; Bouffard and Perga 2016). In the shallower regions of a lake, the labile fraction is decomposed quickly in the water column or precipitates quickly to the sediment. Conversely, the organic matter in the deeper sediments consists mainly of more refractory organic carbon and the mineralization rate decreases with increasing lake depth (Sobek 
et al. 2009; Arndt et al. 2013). Similar observations were made for a marine system in the St. Lawrence Estuary (Alkhatib et al. 2012).

The deepening of the sediment oxic zone with increasing lake depth is fully consistent with this interpretation. While easily mineralized organic matter is more abundant in shallower sediments, the observed decrease in SOU with depth in Lake Geneva is strong evidence that the deeper parts of the lake are covered with more refractory organic matter which leads to lower mineralization activity and subsequently deeper sediment oxic zones. A similar deepening of the oxic zone was noticed in the studies of Müller et al. (2003) of the eutrophic Lake Sempach and by Maerki et al. (2006) of Lake Baikal. Also in Lake Erie, Bouffard et al. (2013) reported an average SOU of $0.46 \mathrm{~g}_{\mathrm{DO}} \mathrm{m}^{-2} \mathrm{~d}^{-1}$, whereas measurements in sediment cores obtained at the center of the lake resulted in a SOU of only $\sim 0.2 \mathrm{~g}_{\mathrm{DO}} \mathrm{m}^{-2}$ $\mathrm{d}^{-1}$ (Smith and Matisoff 2008) indicating a considerable decrease in SOU with lake depth.

In addition to implications for $F_{\text {red }}$ and sediment-water oxygen dynamics, the sediment oxic zone depth is of particular interest for fish eggs, which only survive under oxic conditions. Given the typically thin oxic zone in the upper sediments, fish egg survival is not guaranteed even if DO concentrations in the overlaying water remain relatively high. Fish eggs sinking even slightly into the sediment can easily experience anoxic conditions which are detrimental to their survival (Ventling-Schwank and Müller 1991). Swiss federal law therefore requires a minimum of $4 \mathrm{mg} \mathrm{L}^{-1}$ DO in natural waters to facilitate natural fish reproduction. In Lake Geneva, however, the Lake Char (Salvelinus umbla) population is still not able to naturally reproduce and is artificially stocked, despite decades of reoligotrophication during which hypoxia occurred only rarely (Caudron et al. 2014). The thin sediment oxic zone observed during the current study, which was found to be particularly prevalent in the shallower hypolimnetic sediments, could explain this phenomenon (Ventling-Schwank and Müller 1991).

In Lake Geneva, the majority of soluble, reduced substances are mostly oxidized within the thin oxic zone which prevents these species from diffusing into the water column. Thus, three sediment cores (S1, S2, S3) were taken in close proximity to the microprofile measurement sites (between $100 \mathrm{~m}$ and $400 \mathrm{~m}$ distance) to allow for comparison of SOU and $F_{\text {red }}$. At $40 \mathrm{~m}$ depth, $F_{\text {red }}$ was less than $5 \%$ of SOU (Fig. 8). This fraction increases with increasing lake depth, as SOU decreases while $F_{\text {red }}$ remained relatively constant, but was still below $10 \%$ at $133 \mathrm{~m}$. Thus, reduced substances might play a more important role in the deep hypolimnion. At $224 \mathrm{~m}$, SOU was only $0.14 \mathrm{~g}_{\mathrm{DO}} \mathrm{m}^{-2} \mathrm{~d}^{-1}$. However, SOU varied considerably between profiles at this site and the bulk BBL DO concentration was with $4.5 \mathrm{mg} \mathrm{L}^{-1}$ lower than average, both of which could have led to an underestimation of SOU. The averaged $F_{\text {red }}$ of the eight cores (Table 2) was
$0.049 \mathrm{~g}_{\mathrm{DO}}^{\mathrm{eq}} \mathrm{m}^{-2} \mathrm{~d}^{-1}$ or only $3.6 \%$ of the total AHM of $1.34 \mathrm{~g}_{\mathrm{DO}} \mathrm{m}^{-2} \mathrm{~d}^{-1}$.

Ultimately, reduced substances were found to play only a minor role for the overall hypolimnetic oxygen depletion, expressed as AHM, in Lake Geneva despite high primary production. Müller et al. (2012a) reported relative contributions of up to $80 \%$ of AHM in very shallow small- or mediumsized lakes. In Steinsberger et al. (2017), a direct relationship is documented between the relative importance of reduced substances, mean hypolimnion depth, and the organic carbon content of the sediment. Deeper hypolimnia of lakes correspond to larger DO reservoirs and smaller sediment surface to water volume ratios $(\alpha)$. The mean hypolimnion depth of Lake Geneva is much higher than those of the lakes discussed in Müller et al. (2012a) and hypoxic conditions are found only occasionally in the deepest layers; hence, the contribution of $F_{\text {red }}$ to AHM is low. The increased sediment oxic zone depth in the deeper hypolimnion of Lake Geneva confirms that organic matter mineralization is largely completed in the upper oxic zone of the lake and oxic respiration is the dominant pathway of organic matter mineralization. Consequently, $F_{\text {red }}$ values are quite low.

The results of this deep lake study are in perfect agreement with observations from shallow lakes (Müller et al. 2012a) and explain how the very high AHM rate in Lake Geneva is a consequence of the large deep hypolimnetic reservoir of DO which facilitates persistently high DO concentrations that drive the mineralization of settled organic matter. As deep lakes are less likely to become anoxic above the sediment, they favor the more efficient process of oxic respiration for organic matter mineralization in the sediment.

\section{Water column mineralization}

Oxygen depletion was also quantified by the monthly DO profiles measured by CIPEL. The mean AHM calculated below a depth of $15 \mathrm{~m}$ (corresponding to a hypolimnion area of $534 \mathrm{~km}^{2}$; i.e., $92 \%$ of the surface area) between 1970 and 2012 was $1.34 \pm 0.34 \mathrm{~g}_{\mathrm{DO}} \mathrm{m}^{-2} \mathrm{~d}^{-1}$. With a depletion period during summer of $\sim 180 \mathrm{~d}$, this corresponds to an annual loss of $1.29 \times 10^{5} t$ of DO per summer stratification period. Assuming a Redfield ratio of 138 moles of $\mathrm{O}_{2}$ per 106 mineralized moles of carbon C (Redfield 1958), this relates to a mineralization rate of $370 \mathrm{mg} \mathrm{C} \mathrm{m}^{-2} \mathrm{~d}^{-1}$. Graham et al. (2016) reported an annual gross sedimentation flux of organic matter between $285 \mathrm{mg} \mathrm{C} \mathrm{m}^{-2} \mathrm{~d}^{-1}$ and $595 \mathrm{mg} \mathrm{C} \mathrm{m}^{-2} \mathrm{~d}^{-1}$ for the years 2009 and 2010, which is in excellent agreement with our estimates based on the DO consumption.

While the volume-averaged AHM is in good agreement with the expectations based on the organic matter flux, it gives no information about the vertical distribution of DO depletion. TOD during summer decreased rapidly in the first $100 \mathrm{~m}$, remained constant over $\sim 150 \mathrm{~m}$, and then increased again toward the maximum depth of the lake (Fig. 1). According to Livingstone and Imboden (1996), TOD can be 
separated into contributions proportional to (1) the water volume and (2) the sediment surface. While the areal contribution depends on lake geometry, specifically on the sediment surface to water volume $\alpha$ (Livingstone and Imboden 1996), the volumetric contribution is independent from the morphology. The strong increase in $\alpha$ with depth explains the increase in TOD below $250 \mathrm{~m}$. The model of Livingstone and Imboden (1996), however, assumes the volumetric and areal fraction of the TOD to be constant over the hypolimnion and, therefore, cannot explain the observed decrease in the upper layers. The trend of SOU decreasing with lake depth, as shown in Fig. 7, partially explains the decreasing TOD. However, even if the oxygen depletion caused by the sediment $(\alpha \cdot$ SOU) is subtracted from TOD, the remaining fraction, which can now be interpreted as water column mineralization (WCM), still shows a decreasing trend in the upper hypolimnion. As the quality of organic matter does not significantly differ between the water column and the upper sediment, it is reasonable to assume that the decrease in WCM with depth is a result of the same process causing decreasing SOU with depth, with organic matter mineralization largely occurring in the more oxic zones via oxic respiration.

\section{Conceptual model of oxygen depletion}

The observed variations in SOU and TOD with depth were used to build the foundation of a conceptual model of basinscale DO depletion based on the deductive model of Livingstone and Imboden (1996). TOD can be separated in a watervolume-proportional term, WCM $\left(\mathrm{g} \mathrm{m}^{-3} \mathrm{~d}^{-1}\right)$, and a sediment area-proportional term which consists of $\alpha$, SOU, and $F_{\text {red }}\left(\mathrm{g}_{\text {DO }}^{\text {eq }} \mathrm{m}^{-2} \mathrm{~d}^{-1}\right)$ :

$$
\mathrm{TOD}=\mathrm{WCM}+\alpha\left(\mathrm{SOU}+F_{\mathrm{Red}}\right)
$$

where $\alpha\left[\mathrm{m}^{-1}\right]$ again is the sediment surface to water volume ratio (Fig. 2). In the following analysis, $F_{\text {Red }}$ will be considered as a part of the SOU since the net effect of SOU and $F_{\text {Red }}$ on TOD is system-analytically the same and $F_{\text {red }}$ was found to be negligible for most parts of Lake Geneva. Equation $3 \mathrm{a}$ then simplifies to

$$
\mathrm{TOD}=\mathrm{WCM}+\alpha \mathrm{SOU}
$$

Assuming that the DO depletion rate is a sum of (1) an exponentially decreasing contribution caused by easily degradable organic material and (2) a constant refractory contribution of slowly degrading organic matter, SOU, and WCM can be described as:

$$
\begin{gathered}
\mathrm{SOU}=S_{1}+S_{2} \mathrm{e}^{\frac{-\left(z-z_{0}\right)}{z_{\tau}}} \\
\mathrm{WCM}=W_{1}+W_{2} \mathrm{e}^{\frac{-\left(z-z_{0}\right)}{z_{\tau}}}
\end{gathered}
$$

where $S_{1}$ and $W_{1}$ are the contribution of the slowly degrading part of the organic matter and $S_{2}$ and $W_{2}$ describe the

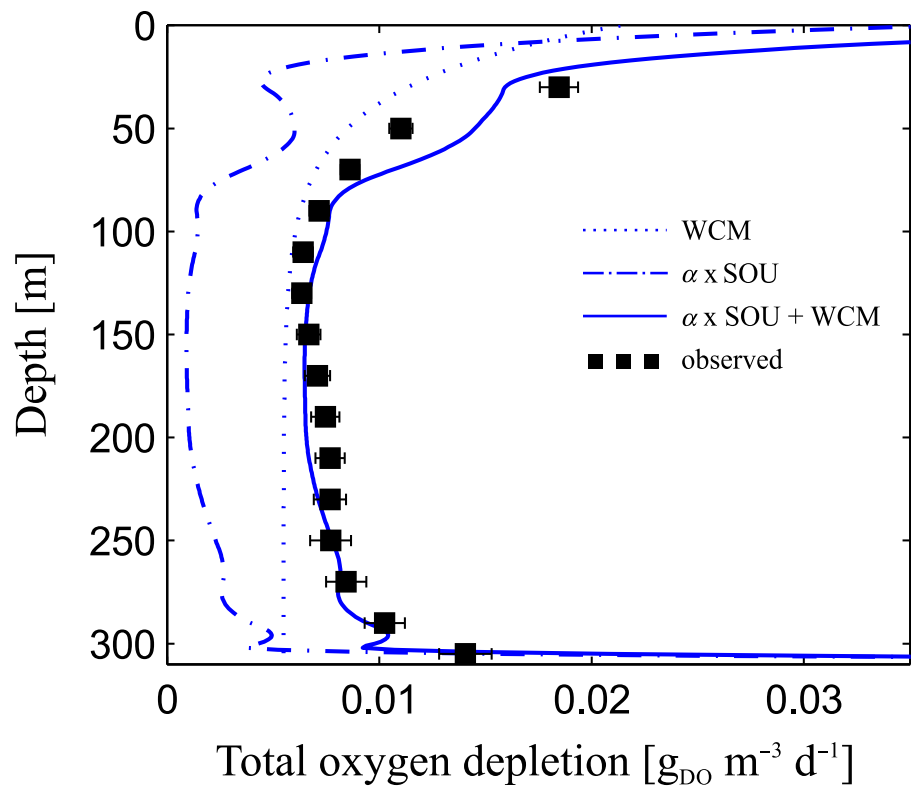

Fig. 9. TOD (= $\alpha S O U+W C M), W C M$ and SOU as functions of depth. $\alpha$ is the ratio of sediment surface to water volume.

contribution of the fast degrading fraction at the lower end of the productive zone (depth $z_{0}$; here set to $30 \mathrm{~m}$ ) which decrease exponentially with depth $z$. The degradation depth scale $z_{\tau}$ indicates where the contribution of the fast degrading part is reduced to $1 / \mathrm{e}$ of the value at $z_{0}$. The degradation depth scale and is assumed to be the same for WCM and SOU.

The parameters $S_{1}, S_{2}$ and $Z_{\tau}$ were based on observational results from microprofile measurements. The best fit was found for $S_{1}=0.18 \pm 0.06 \mathrm{~g} \mathrm{~m}^{-2} \mathrm{~d}^{-1} ; S_{2}=1.45 \pm 0.18 \mathrm{~g} \mathrm{~m}^{-2}$ $\mathrm{d}^{-1}$, and $z_{\tau}=30 \pm 8 \mathrm{~m}$. Estimated values of $\alpha \mathrm{SOU}$ were subtracted from the mean TOD values determined by the longterm data and the result was considered to be the fraction of TOD caused by WCM. Equation 5 was then fitted to the residual, leading to values of $W_{1}=0.0055 \pm 0.0004 \mathrm{~g} \mathrm{~m}^{-3}$ $\mathrm{d}^{-1} ; W_{2}=0.0058 \pm 0.0012 \mathrm{~g} \mathrm{~m}^{-3} \mathrm{~d}^{-1}$. In Fig. 9, the model result is shown in comparison to the values of the monitoring data.

Unlike Livingstone and Imboden (1996), this model takes the vertical variability in TOD into account. This allows for a more accurate description of the vertical structure of oxygen depletion. Rhodes et al. (2017) showed that the Livingstone and Imboden (1996) model describes the oxygen depletion in Lake Constance below $150 \mathrm{~m}$ well. However, our results show that the highest variability in oxygen depletion can be observed above $\sim 150 \mathrm{~m}$. Müller et al. (2012a) describe the AHM based on a box model which takes $F_{\text {red }}$ and the SOU in the upper layer of the sediment into account. Their model neglects spatial variabilities and does not consider the mineralization within the water column explicitly. Hence, it 
reproduces the AHM of shallow eutrophic lakes very well, but fails to describe the processes in deep lakes. A comparison of the findings of Müller et al. $(2012 a, b)$ with the results of this study shows an important difference between shallow and deep lakes: while the oxygen depletion in shallow lakes is mainly controlled by the sediments with high values of $F_{\text {red, }}$ TOD of large lakes is dominated by oxic respiration. This implies that the mineralization of organic matter is mostly completed in the upper part of the sediments in deep lakes and changes in productivity might affect oxygen depletion more rapidly. Additional studies focused on the relative importance of SOU for the TOD in different lakes based on Eqs. 1-5 and the influence of changes in primary production might further enhance understanding of the development of oxygen depletion rates.

As the model relies on several fit parameters $\left(S_{1}, S_{2}, W_{1}\right.$, $W_{2}$, and $z_{\tau}$ ), the exact quantification of an individual parameter is complex given the relatively large variations in the data. The parameters $S_{1}, S_{2}$, and $z_{\tau}$ were determined experimentally; thus, the estimation of these three parameters is based on relatively few measurements from the northern part of the deep basin Lake Geneva and assumes horizontal homogeneity. In particular, the high error in the parameters $S_{1}$ and $Z_{\tau}$ may be attributed to the large uncertainty of SOU in the deeper layers of the lake, where only one measurement was performed. Additional sources of uncertainty in these parameters include possible localized influences that were outside the scope of this study, such vertical variability resulting from Rhône River influent or nutrient loading due to wastewater effluent.

Regardless of intrinsic uncertainties in the fit parameters, the model is able to sufficiently reproduce TOD and allows for the separation of the volumetric and areal contributions. The model deviates in regions with large gradients of $\alpha$, namely near $50 \mathrm{~m}$ and at maximum depth. At these depths, the increased SOU is smoothed by the effect of turbulent vertical diffusion. In theory, Eqs. 1-5 are only valid for nondiffusive water columns. However, this is not always strictly fulfilled, especially in deep layers where turbulent diffusion and DO gradients are comparatively large.

Between $100 \mathrm{~m}$ and $250 \mathrm{~m}$ depth, the proposed model approximates TOD with a root mean square error of only $7 \%$. Larger deviations are observed above and below these depths. Below $250 \mathrm{~m}$, the error is mainly due to the neglect of vertical diffusion. Diffusion leads to a net flux of DO from regions with low depletion rates to regions with higher depletion rates. Since the highest depletion rates are expected in the deepest layers with enhanced values for $\alpha$, neglecting diffusion leads to an underestimate of SOU in these regions (as shown in Fig. 9). Similarly, the local bathymetry with an increase in $\alpha$ at 50 m leads to an overestimation in the model above $\sim 100 \mathrm{~m}$. Increased mixing due to gyre formation and basin-scale internal waves may also explain parts of these deviations since the resulting DO transport to the deeper layers is not considered.

According to this simplified model, $68 \% \pm 6 \%$ of TOD takes place in the interior of the water column while $32 \% \pm$ $6 \%$ occurs at the sediment surface. These results compare well with values found in the literature. Bouffard et al. (2013) found SOU to be responsible for 51-53\% of the TOD for Lake Erie (maximum depth: $64 \mathrm{~m}$ ). Beutel et al. (2007) reported $40-50 \%$ for the San Vicente Reservoir in California (maximum depth: $58 \mathrm{~m}$ ). In general, the importance of SOU decreases with lake depth since smaller values of $\alpha$ favor mineralization in the water column. Consequently, the AHM in more shallow lakes can be explained solely by SOU as exemplified by Müller et al. (2012a).

\section{Conclusions}

The different contributors to the TOD in the hypolimnion of Lake Geneva were measured and conceptually explained. For the first time, SOU was measured autonomously across the SWI via microprofiling at up to $224 \mathrm{~m}$ depth in lakes. In parallel, sediment cores were retrieved to measure the flux of reduced substances from deeper sediment layers into the overlaying water column. The findings were complemented by more than $40 \mathrm{yr}$ of historical oxygen monitoring data. We conclude as follows:

- The SOU rate decreased from $1.08 g_{\text {DO }}^{\text {eq }} \mathrm{m}^{-2} \mathrm{~d}^{-1}$ at $43 \mathrm{~m}$ to only $0.14 g_{\text {DO }}^{\text {eq }} \mathrm{m}^{-2} \mathrm{~d}^{-1}$ at $224 \mathrm{~m}$ depth. As SOU decreased, the thickness of the sediment oxic zone increased. This observation can be attributed to decreasing availability of labile organic carbon. Besides the implications for the oxygen budget of the entire lake, the varying SOU and the corresponding sediment oxic zone are highly relevant for the lake ecosystem as fish egg survival depends on oxic conditions in the upper sediment. Within the sediment, the flux of reduced substances $\left(F_{\text {red }}\right)$ was extremely low at all eight sampling locations. This confirms that oxic respiration of organic carbon, as opposed to oxidation of reduced substances originating from anoxic mineralization, is the dominant pathway of DO consumption in deep lakes.

- The analysis of long-term monitoring data suggests that WCM shows a similar decrease with depth. A basin-scale depletion model was developed to explain the variation of the TOD with depth based on parametrizations for SOU,

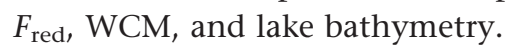

- Based on the developed basin-scale depletion model, the relative importance of SOU and WCM can be estimated. Compared to shallow lakes, the relative importance of WCM ( $\sim 70 \%$ of TOD) is high. This agrees with the expectation that SOU becomes less important with increasing lake depth and, in turn, a decreasing ratio of sediment surface to water volume. 
- The exponential decrease of oxygen depletion in the upper hypolimnion of Lake Geneva provides evidence of the critical role of the quality of organic matter in oxygen depletion processes and carbon cycling. Detailed analyses of the fraction of labile and refractory organic matter at different lake depths could further improve understanding of oxygen depletion in deep lakes.

\section{References}

Alkhatib, M., C. J. Schubert, P. A. del Giorgio, Y. Gelinas, and M. F. Lehmann. 2012. Organic matter reactivity indicators in sediments of the St. Lawrence Estuary. Estuar. Coast. Shelf Sci. 102-103: 36-47. doi:10.1016/ j.ecss.2012.03.002

Anneville, O., and J. P. Pelletier. 2000. Recovery of Lake Geneva from eutrophication: Quantitative response of phytoplankton. Arch. Hydrobiol. 148: 607-624. doi: 10.1127/archiv-hydrobiol/148/2000/607

Arndt, S., B. B. Jørgensen, D. E. LaRowe, J. J. Middelburg, R. D. Pancost, and P. Regnier. 2013. Quantifying the degradation of organic matter in marine sediments: A review and synthesis. Earth Sci. Rev. 123: 53-86. doi:10.1016/ j.earscirev.2013.02.008

Beutel, M., I. Hannoun, J. Pasek, and K. B. Kavanagh. 2007. Evaluation of hypolimnetic oxygen demand in a large eutrophic raw water reservoir, San Vicente Reservoir, Calif. J. Environ. Eng. 133: 130-138. doi:10.1061/ (ASCE)0733-9372(2007)133:2(130)

Bouffard, D., J. D. Ackerman, and L. Boegman. 2013. Factors affecting the development and dynamics of hypoxia in a large shallow stratified lake: Hourly to seasonal patterns. Water Resour. Res. 49: 2380-2394. doi:10.1002/wrcr.20241

Bouffard, D., and M.-E. Perga. 2016. Are flood-driven turbidity currents hot spots for priming effect in lakes? Biogeosciences 13: 3573-3584. doi:10.5194/bg-13-3573-2016

Bryant, L. D., C. Lorrai, D. McGinnis, A. Brand, A. Wüest, and J. C. Little. 2010a. Variable sediment oxygen uptake in response to dynamic forcing. Limnol. Oceanogr. 55: 950-964. doi:10.4319/1o.2009.55.2.0950

Bryant, L. D., D. F. McGinnis, C. Lorrai, A. Brand, J. C. Little, and A. Wüest. 2010b. Evaluating oxygen fluxes using microprofiles from both sides of the sediment-water interface. Limnol. Oceanogr.: Methods 8: 610-627. doi: 10.4319/lom.2010.8.0610

Bryant, L. D., P. A. Gantzer, and J. C. Little. 2011. Increased sediment oxygen uptake caused by oxygenation-induced hypolimnetic mixing. Water Res. 45: 3692-3703. doi: 10.1016/j.watres.2011.04.018

Caudron, A., E. Lasne, C. Gillet, J. Guillard, and A. Champigneulle. 2014. Thirty years of reoligotrophication do not contribute to restore self-sustaining fisheries of Arctic charr, Salvelinus alpinus, in Lake Geneva. Fish. Res. 154: 165-171. doi:10.1016/j.fishres.2014.01.023
Cornett, R. J., and F. H. Rigler. 1979. Hypolimnetic oxygen deficits: Their prediction and interpretation. Science 205: 580-581. doi:10.1126/science.205.4406.580

Cornett, R. J., and F. H. Rigler. 1980. The areal hypolimnetic oxygen deficit: An empirical test of the model. Limnol. Oceanogr. 25: 672-679. doi:10.4319/lo.1980.25.4.0672

Delebecque, A. 1898. Les lacs français, Typographie Chamerot et Renouard, Paris.

Diaz, R. J. 2001. Overview of hypoxia around the world. J. Environ. Qual. 30: 275-281. doi:10.2134/jeq2001.302275x

Epping, E. H. G., and W. Helder. 1997. Oxygen budgets calculated from in situ oxygen microprofiles for Northern Adriatic sediments. Cont. Shelf Res. 17: 1737-1764. doi: 10.1016/S0278-4343(97)00039-3

Fang, X., and H. G. Stefan. 2009. Simulations of climate effects on water temperature, dissolved oxygen, and ice and snow covers in lakes of the contiguous United States under past and future climate scenarios. Limnol. Oceanogr. 54: 2359-2370. doi:10.4319/lo.2009.54.6_part_2.2359

Forel, F. 1895. Le Léman: Monographie Limnologique. Toma II. Mécanique, Hydraulique, Thermique, Optique, Acoustique, Chemie. F. Rouge.

Frenzel, P., B. Thebrath, and R. Conrad. 1990. Oxidation of methane in the oxic surface layer of a deep lake sediment (Lake Constance). FEMS Microbiol. Lett. 73: 149-158. doi: 10.1111/j.1574-6968.1990.tb03935.x

Friedrich, J., and others. 2014. Investigating hypoxia in aquatic environments: Diverse approaches to addressing a complex phenomenon. Biogeosciences 11: 1215-1259. doi:10.5194/bg-11-1215-2014

Gelda, R. K., M. T. Auer, and S. W. Effler. 1995. Determination of sediment oxygen demand by direct measurement and by inference from reduced species accumulation. Mar. Freshw. Res. 46: 81-88. doi:10.1071/MF9950081

Graham, N. D., D. Bouffard, and J.-L. Loizeau. 2016. The influence of bottom boundary layer hydrodynamics on sediment focusing in a contaminated bay. Environ. Sci. Pollut. Res. 23: 25412-25426. doi:10.1007/s11356-0167715-9

Gudasz, C., D. Bastviken, K. Steger, K. Premke, S. Sobek, and L. J. Tranvik. 2010. Temperature-controlled organic carbon mineralization in lake sediments. Nature 466: 478481. doi:10.1038/nature09186

Hutchinson, C. E. 1957. A treatise of limnology. Geography, physics and chemistry, v. 1. Wiley.

Jenny, J.-P., F. Arnaud, B. Alric, J.-M. Dorioz, P. Sabatier, M. Meybeck, and M.-E. Perga. 2014. Inherited hypoxia: A new challenge for reoligotrophicated lakes under global warming. Global Biogeochem. Cycles 28: 1413-1423. doi: 10.1002/2014GB004932

Jørgensen, B. B., and N. P. Revsbech. 1985. Diffusive boundary layers and the oxygen uptake of sediments and detritus. Limnol. Oceanogr. 30: 111-122. doi:10.4319/ lo.1985.30.1.0111 
Kristensen, E., and M. Holmer. 2001. Decomposition of plant materials in marine sediment exposed to different electron acceptors $\left(\mathrm{O}_{2}, \mathrm{NO}_{3}^{-}\right.$, and $\left.\mathrm{SO}_{4}^{2-}\right)$, with emphasis on substrate origin, degradation kinetics, and the role of bioturbation. Geochim. Cosmochim. Acta 65: 419-433. doi: 10.1016/S0016-7037(00)00532-9

Kubáň, P., H. T. A. Nguyen, M. Macka, P. R. Haddad, and P. C. Hauser. 2007. New fully portable instrument for the versatile determination of cations and anions by capillary electrophoresis with contactless conductivity detection. Electroanalysis 19: 2059-2065. doi:10.1002/elan.200703908

Livingstone, D. M., and D. M. Imboden. 1996. The prediction of hypolimnetic oxygen profiles: A plea for a deductive approach. Can. J. Fish. Aquat. Sci. 53: 924-932. doi: 10.1139/f95-230

Loizeau, J.-L., and J. Dominik. 2005. The history of eutrophication and restoration of Lake Geneva. Terre Environ. 50: 43-56.

Lorke, A., B. Müller, M. Maerki, and A. Wüest. 2003. Breathing sediments: The control of diffusive transport across the sediment-water interface by periodic boundary-layer turbulence. Limnol. Oceanogr. 48: 2077-2085. doi: 10.4319/1o.2003.48.6.2077

Maerki, M., B. Müller, and B. Wehrli. 2006. Microscale mineralization pathways in surface sediments: A chemical sensor study in Lake Baikal. Limnol. Oceanogr. 51: 13421354. doi:10.4319/1o.2006.51.3.1342

Matzinger, A., B. Müller, P. Niederhauser, M. Schmid, and A. Wüest. 2010. Hypolimnetic oxygen consumption by sediment-based reduced substances in former eutrophic lakes. Limnol. Oceanogr. 55: 2073-2084. doi:10.4319/ lo.2010.55.5.2073

Müller, B., Y. Wang, M. Dittrich, and B. Wehrli. 2003. Influence of organic carbon decomposition on calcite dissolution in surficial sediments of a freshwater lake. Water Res. 37: 4524-4532. doi:10.1016/S0043-1354(03)00381-6

Müller, B., L. D. Bryant, A. Matzinger, and A. Wüest. 2012a. Hypolimnetic oxygen depletion in eutrophic lakes. Environ. Sci. Technol. 46: 9964-9971. doi:10.1021/es301422r

Müller, B., L. Och, and A. Wüest. 2012b. Entwicklung des Phosphorhaushalts und der Sauerstoffzehrung im Sempacher- und Baldeggersee. EAWAG report. Eawag, Swiss Federal Institute of Aquatic Science and Technology.

Müller, B., R. Gächter, and A. Wüest. 2014. Accelerated water quality improvement during oligotrophication in perialpine lakes. Environ. Sci. Technol. 48: 6671-6677. doi: 10.1021/es4040304

North, R. P., R. L. North, D. M. Livingstone, O. Köster, and R. Kipfer. 2014. Long-term changes in hypoxia and soluble reactive phosphorus in the hypolimnion of a large temperate lake: Consequences of a climate regime shift. Glob. Chang. Biol. 20: 811-823. doi:10.1111/gcb.12371

Rast, W., and G. F. Lee. 1978. Summary analysis of the North American (US portion) OECD eutrophication project:
Nutrient loading - lake response relationships and trophic state indices. U.S. Environmental Protection Agency.

Razmi, A. M., D. A. Barry, R. Bakhtyar, D. Le, A. Dastgheib, U. Lemmin, and A. Wüest. 2013. Current variability in a wide and open lacustrine embayment in Lake Geneva (Switzerland). J. Great Lakes Res. 39: 455-465. doi: 10.1016/j.jglr.2013.06.011

Redfield, A. C. 1958. The biological control of chemical factors in the environment. Am. Sci. 46: 205-221.

Rhodes, J., H. Hetzenauer, M. A. Frassl, K.-O. Rothhaupt, and K. Rinke. 2017. Long-term development of hypolimnetic oxygen depletion rates in the large Lake Constance. Ambio 46: 554-565. doi:10.1007/s13280-017-0896-8

Rippey, B., and C. McSorley. 2009. Oxygen depletion in lake hypolimnia. Limnol. Oceanogr. 54: 905-916. doi:10.4319/ 10.2009.54.3.0905

Røy, H., M. Huettel, and B. B. Jørgensen. 2004. Transmission of oxygen concentration fluctuations through the diffusive boundary layer overlying aquatic sediments. Limnol. Oceanogr. 49: 686-692. doi:10.4319/lo.2004.49.3.0686

Rucinski, D. K., D. Beletsky, J. V. DePinto, D. J. Schwab, and D. Scavia. 2010. A simple 1-dimensional, climate based dissolved oxygen model for the central basin of Lake Erie. J. Great Lakes Res. 36: 465-476. doi:10.1016/j.jglr.2010.06.002 Rucinski, D. K., J. V. DePinto, D. Scavia, and D. Beletsky. 2014. Modeling Lake Erie's hypoxia response to nutrient loads and physical variability. J. Great Lakes Res. 40: 151161. doi:10.1016/j.jglr.2014.02.003

Savoye, L., P. Quetin, and A. Klein. 2015. Evolution physicochimique des eaux du Léman, données météorologiques, apports par les affluents au Léman et au Rhône à l'aval de Genève, p. 21-51. Rapp. Comm. Int. Prot. Eaux Léman Contre Pollut, Commission internationale pour la protection des eaux du Léman, Campagne 2014.

Scavia, D., and others. 2014. Assessing and addressing the reeutrophication of Lake Erie: Central basin hypoxia. J. Great Lakes Res. 40: 226-246. doi:10.1016/j.jglr.2014.02.004

Schindler, D. W. 2006. Recent advances in the understanding and management of eutrophication. Limnol. Oceanogr. 51: 356-363. doi:10.4319/lo.2006.51.1_part_2.0356

Schwefel, R., A. Gaudard, A. Wüest, and D. Bouffard. 2016. Effects of climate change on deep-water oxygen and winter mixing in a deep lake (Lake Geneva)-comparing observational findings and modeling. Water Resour. Res. 52: 8811-8826. doi:10.1002/2016WR019194

Schwefel, R., M. Hondzo, A. Wüest, and D. Bouffard. 2017. Scaling oxygen microprofiles at the sediment interface of deep stratified waters. Geophys. Res. Lett. 44: 1340-1349. doi:10.1002/2016GL072079

Smith, D. A., and G. Matisoff. 2008. Sediment oxygen demand in the central basin of Lake Erie. J. Great Lakes Res. 34: 731-744. doi:10.1016/S0380-1330(08)71614-9

Sobek, S., E. Durisch-Kaiser, R. Zurbrügg, N. Wongfun, M. Wessels, N. Pasche, and B. Wehrli. 2009. Organic carbon 
burial efficiency in lake sediments controlled by oxygen exposure time and sediment source. Limnol. Oceanogr. 54: 2243-2254. doi:10.4319/1o.2009.54.6.2243

Steinsberger, T., M. Schmid, A. Wüest, R. Schwefel, B. Wehrli, and B. Müller. 2017. Organic carbon mass accumulation rate regulates the flux of reduced substances from the sediments of deep lakes. Biogeosciences 14: 3275-3285. doi:10.5194/bg-14-3275-2017

Thienemann, A. 1928. Der Sauerstoff im eutrophen und oligotrophen See: Ein Beitrag zur Seetypenlehre. E. Schweizerbart.

Torres, N. T., P. C. Hauser, G. Furrer, H. Brandl, and B. Müller. 2013. Sediment porewater extraction and analysis combining filter tube samplers and capillary electrophoresis. Environ. Sci. Process. Impacts 15: 715-720. doi: 10.1039/c3em00068k

Ventling-Schwank, A., and R. Müller. 1991. Survival of coregonid (Coregonus sp.) eggs in Lake Sempach, Switzerland. Verh. int. Ver. Limnol. 24: 2451-2454.

Vivier, P. 1944. Température et oxygène dissous dans le Léman français. Trav. lab. d'hydrobiol. l'Univ. Grenoble 20: 25-35.

Wüest, A., F. S. Anselmetti, J. S. Arey, B. W. Ibelings, J. L. Loizeau, T. Vennemann, and U. Lemmin. 2014. Into the abyss of Lake Geneva: The elemo interdisciplinary field investigation using the MIR submersibles. Aquat. Sci. 76: S1-S6. doi:10.1007/s00027-014-0353-8

\section{Acknowledgments}

The authors would like to thank Theo Baracchini, Adrien Gaudard, Patrick Kathriner, Sébastien Lavanchy, Vincent Nouchi, Natacha Pasche, Love Råman Vinnå, Katrina Schuler, Michael Schurter, Oscar Sepulveda Steiner, and Hugo Ulloa for their help during the field measurement campaigns. The authors also acknowledge the encouraging and helpful comments of three anonymous reviewers. The Delft3D model was provided by DELTARES (NL) and we appreciate their support and advice. Long-term monitoring data were provided by the Commission International pour la Protection des Eaux du Léman (CIPEL) and the Information System of the SOERE OLA (http://si-ola.inra.fr), INRA Thonon-les-Bains. The first author was supported by the Swiss National Science Foundation grants 200021_146652 and 200020_165517. The second author was supported by the Swiss National Science Foundation grant 200021_146234.

\section{Conflict of Interest}

None declared.
Submitted 14 December 2016

Revised 24 June 2017

Accepted 08 September 2017

Associate editor: Francisco Rueda 